\title{
CD4 Recovery and Survival among Adults Co-infected with HIV and Hepatitis B or C Virus, Ho Chi Minh City, Vietnam
}

\author{
Hao Duong ${ }^{1,2, *}$, Son Nguyen ${ }^{1}$, Ray Shiraishi ${ }^{3}$, Hung Trinh ${ }^{4}$, Hanh Vo ${ }^{5}$, Thu-Van Tieu ${ }^{4}, H_{u n g} \operatorname{Van}^{4}$, \\ Thinh Tran ${ }^{4}$, Marta Ackers $^{1}$, Siobhán O'Connor ${ }^{6}$ \\ ${ }^{1}$ U.S. Centers for Disease Control and Prevention, Division of Global HIV and TB, Hanoi, Vietnam \\ ${ }^{2}$ The Partnership for Health Advancement in Vietnam (HAIVN), HCMC, Vietnam \\ ${ }^{3}$ U.S. Centers for Disease Control and Prevention, Division of Global HIV and TB, Atlanta, GA, USA \\ ${ }^{4}$ The Provincial AIDS Committee (PAC), Ho Chi Minh City (HCMC), Vietnam \\ ${ }^{5}$ Pham Ngoc Thach University of Medicine, Ho Chi Minh City (HCMC), Vietnam \\ ${ }^{6}$ U.S. Centers for Disease Control and Prevention, Division of Viral Hepatitis, Atlanta, GA, USA
}

Copyright $\subseteq 2017$ by authors, all rights reserved. Authors agree that this article remains permanently open access under the terms of the Creative Commons Attribution License 4.0 International License

\begin{abstract}
This study assessed associations between hepatitis $\mathrm{B}$ and $\mathrm{C}$ virus (HBV, HCV) and increases in CD4 count and survival among $4316 \mathrm{HIV}$-infected patients on non-tenofovir (TDF)-based antiretroviral treatment (ART) in Ho Chi Minh City, Vietnam during 2006-2010, using mixed-effects model and survival analysis. More than half of patients $(52.4 \%)$ participating in the study were $\mathrm{HBsAg}$-negative/anti-HCV-negative, $\quad 9.0 \% \quad \mathrm{HBsAg}$ positive/anti-HCV-negative, and $38.6 \%$ anti-HCV-positive. Anti-HCV-positive males had smaller increases in CD4 count during the first two years of ART, but larger increases between two and three years after ART initiation than anti-HCV-negative females (regardless of HBsAg status) and HBsAg-negative/anti-HCV-negative males. Magnitude of the differences was small. Overall mortality rate was 15 per 1000 person-years; HBsAg and anti-HCV status were not significantly associated with mortality. Co-infection with HBV (HBsAg-positive) and/or exposure to $\mathrm{HCV}$ (anti-HCV-positive) does not seem to have substantial effects on outcomes of patients on non-TDF-containing ART during a median follow-up of 1.72 years. It may take a longer time for assessing effects of co-infection with HBV and/or HCV on ART outcomes. Such assessments should focus on those with positive HCV RNA, instead of positive anti-HCV.
\end{abstract}

Keywords HIV, Hepatitis B Virus, Hepatitis C Virus, ART, CD4, Mortality, Survival

\section{Introduction}

Viet Nam is highly endemic for chronic hepatitis B virus
(HBV) infection. Mother-to-child (perinatal) transmission is the most common mode of infection, followed by horizontal transmission from family members and close contacts during early childhood [1]. An estimated $6-25 \%$ of Vietnamese are chronically infected with HBV [2-5]. Hepatitis $\mathrm{C}$ virus (HCV) infection prevalence is lower, estimated at $0.5-4 \%[2,3,6]$. However, higher HBV and $\mathrm{HCV}$ infection prevalences are reported among people living with HIV (PLHIV) and at risk for HIV in Vietnam, ascribed to overlapping behavioral risks for HIV, HBV and $\mathrm{HCV}$ exposures $[3,7,8]$. In a study among people who inject drugs (PWID) in northern Vietnam, prevalence of HIV was $42.4 \%$; of hepatitis B core antibody ( $\mathrm{HBc} \mathrm{Ab}$ ), $80.9 \%$; and of antibody to HCV (anti-HCV), $74.1 \%$ [8]. The 2009-2010 surveillance data among male PWID in 10 Vietnam provinces found $\mathrm{HBsAg}$-positive prevalence of $12 \%$ to $28 \%$ across provinces and combined $\mathrm{HCV}$ antigen/antibody prevalence of $11 \%$ to $87 \%$; $\mathrm{HCV}$ antigen/antibody prevalence was higher among HIV-positive (95.8\%) compared with HIV-negative male PWID (52.2\%) [7]. Previous studies have reported that $\mathrm{HBV}$ and HCV co-infections among PLHIV are associated with increased hepatic disease and overall morbidity and mortality [9-12]. Also CD4 cell recovery was slower among HIV-HCV co-infected patients after ART initiation than those without $\mathrm{HCV}$ co-infection [13].

Antiretroviral therapy (ART) containing lamivudine (3TC) or emtricitabine (FTC) might initially suppress HBV, but HBV resistance can develop [14-19]. Additionally, immune reconstitution with ARV agents that suppress HIV replication can complicate HIV management by activating viral hepatitis (hepatic flare) in the absence of adequate HBV or HCV suppression [15]. Recently, a few small 
HIV/HBV co-infected cohorts in high resource settings have reported effective suppression of both HIV and HBV replication (viral load) with ART containing (TDF + 3TC/FTC + a second NRTI), accompanied by improvement in overall HIV and hepatic health measures $[15,19,20]$. However, few reports from low resource settings are available, where HIV is often more advanced at diagnosis, CD4 counts much lower and HBV infection rates much higher $[21,22]$. ART containing tenofovir with lamivudine/emtricitabine and efavirenz/nevirapine $(\mathrm{TDF}+3 \mathrm{TC} / \mathrm{FTC}+$ EFV/NVP $)$ may also reduce hepatotoxicity associated with ART agents such as stavudine (d4T) [21-25], commonly used first-line ART regimens in Vietnam until 2013. New, well-tolerated and efficacious direct-acting antivirals for $\mathrm{HCV}$ are not yet available in Vietnam [26].

In November 2011, new ART guidelines were decreed by the Viet Nam Ministry of Health (MOH) [27], calling for universal use tenofovir (TDF + 3TC + (efavirenz [EFV] or nevirapine [NVP]) to suppress HIV replication for ART-naïve HIV-infected individuals (first-line ART) and $(\mathrm{TDF}+3 \mathrm{TC}+\mathrm{EFV})$ regimens specifically for $\mathrm{HIV} / \mathrm{HBV}$ co-infected individuals. It further called for switching most individuals already receiving ART without TDF to TDF-based therapy over time. Following it, the HCMC Provincial AIDS Committee (PAC) rapidly implemented this regimen for all ART-naïve PLHIV and PLHIV already receiving ART and increased access to $\mathrm{HBsAg}$ and anti-HCV testing in its HIV outpatient clinics.

We sought to describe increases in absolute CD4 cell counts and survival among HIV-infected patients who initiated ART before tenofovir became a first line regimen in Vietnam and to explore the association of these outcomes with markers of $\mathrm{HBV}$ and $\mathrm{HCV}$ infection.

\section{Methods}

\section{Study Population}

This study analyzed an existing database containing clinical and laboratory information abstracted in late 2010 from medical records of adult PLHIV (aged $\geq 16$ years) who initiated ART during 2006-2010 at 19 community-based adult HIV clinics in HCMC. The 19 clinics administered approximately $67 \%$ of adult ART and HIV care in HCMC during the study period.

Half of the medical charts at each clinic (every other chart) were selected for abstraction $(\mathrm{n}=7021)$. Of those, $4316(61.5 \%)$ charts that had a recorded CD4 count $\leq 3$ months before and at least $1 \mathrm{CD} 4$ count $\geq 2$ months after ART initiation were included in the analysis.

\section{Data Sources}

The database consisted of patient information routinely documented by health care providers in clinic logbooks, and patient charts during clinic visits, including demographics, medical history, injection drug use history, ART initiation date and regimen, clinical signs, laboratory test results (including hepatitis serology) at OPC enrollment; CD4 cell counts before ART initiation and during ART; and status at the time of data abstraction (death, loss to follow-up [LTFU] or transferred). Trained study staff abstracted data onto a data collection form and entered data into Epi Info ${ }^{\mathrm{TM}} 6$.

\section{Variables, Definitions and Outcomes}

$\mathrm{HBsAg}$ and anti-HCV results defined $\mathrm{HBV}$ and $\mathrm{HCV}$ infection status as: (1) no evidence of current $\mathrm{HBV}$ infection or $\mathrm{HCV}$ exposure (HBsAg-negative/anti-HCV-negative); (2) current HBV infection without $\mathrm{HCV}$ exposure (HBsAg-positive/anti-HCV-negative); (3) current or past $\mathrm{HCV}$ infection without evidence of $\mathrm{HBV}$ infection (HBsAg-negative/anti-HCV-positive); and (4) both current $\mathrm{HBV}$ infection and current or past $\mathrm{HCV}$ infection (HBsAg-positive/anti-HCV-positive). Due to the small number of individuals in group (4), groups (3) and (4) were combined to form a category (3b): current or past HCV infection (anti-HCV+), regardless of $\mathrm{HBV}$ infection status (either HBsAgpositive or HBsAg-negative). Abnormal ALT was defined as ALT $>40 \mathrm{U} / \mathrm{L}$ in men and $>31 \mathrm{U} / \mathrm{L}$ in women [28]. Hgb levels of $\geq 11 \mathrm{~g} / \mathrm{dL}$ were categorized as no or mild anemia and $\mathrm{Hgb}<11 \mathrm{~g} / \mathrm{dL}$ as moderate or severe anemia [29]. Body weight was grouped as $<45 \mathrm{~kg}, 45$ to $<50 \mathrm{~kg}, 50$ to $<55 \mathrm{~kg}$, and 55 or greater $(55+) \mathrm{kg}$.

National criteria for ART initiation changed during the study period: CD4 $<200$ cells $/ \mathrm{mm}^{3}$ or World Health Organization (WHO) HIV clinical stage IV (during 2005-9/2009) [30]; or CD4 $<250$ cells $/ \mathrm{mm}^{3}$ or WHO HIV clinical stage III or IV (during 9/2009-11/2011) [31]. We defined ART LTFU as not returning to the clinic within three months of the previous visit according to Circular No. 32/2013/TT-BYT [32]. Outcomes for analysis included CD4 cell response to ART over time (i.e. mean absolute increase in CD4 count) and death.

\section{Statistical methods}

\section{Data Imputation}

Missing data from OPC enrollment for $\mathrm{HBsAg}$, anti-HCV, injection drug use history, HIV clinical stage, $\mathrm{Hgb}$, ALT, body weight and TB status were assumed to be missing at random and multiply imputed via chained equations using "mi impute chained (mlogit)" [33]. Twenty imputed datasets were created and estimates were combined according to Rubin's rules using "mi estimate" procedure [33]. The imputation model included all studied variables. 


\section{Descriptive Analysis}

Proportions, means (standard deviations), and medians (interquartile ranges, IQR) of studied variables were calculated. Wald test in logistic regression was used to compare differences in proportions between genders. Clustering (clinic) was taken into account in the analysis.

Association of HBsAg and Anti-HCV Status with CD4 Recovery

Mixed-effects fractional polynomial regressions were used to examine whether HBsAg-positive or anti-HCV-positive had negative impact on the CD4 cell count increase over time. A three-level model [34] was constructed in which repeated CD4 measures were nested within individuals and individuals were nested within the clinic as follows:

Level 1:

$$
\mathrm{Y}_{\mathrm{tij}}=\pi_{0 \mathrm{ij}}+\pi_{1 \mathrm{ij}}(\text { Time })_{\mathrm{tij}}+\pi_{2 \mathrm{ij}}(\text { Time } \times \ln (\text { Time }))_{\mathrm{tij}}+\mathrm{e}_{\mathrm{tij}}
$$

Level 2:

$$
\begin{aligned}
& \pi_{0 \mathrm{ij}}=\beta_{00 \mathrm{j}}+\beta_{01 \mathrm{j}}(\mathrm{Hep})_{\mathrm{ij}}+\mathrm{r}_{0 \mathrm{ij}} \\
& \pi_{\mathrm{lij}}=\beta_{10 \mathrm{j}}+\beta_{11 \mathrm{j}}\left(\mathrm{Hep}_{\mathrm{ij}}+\mathrm{r}_{\mathrm{ij}}\right.
\end{aligned}
$$

Level 3:

$$
\begin{aligned}
& \beta_{00 \mathrm{j}}=\gamma 000+\mathrm{u} 00 \mathrm{j} \\
& \beta_{10 \mathrm{j}}=\mathrm{\gamma}_{100}+\mathrm{u} 10 \mathrm{j}
\end{aligned}
$$

Where $\mathrm{t}=$ time, $\mathrm{i}=$ patient, and $\mathrm{j}=$ clinic; $\mathrm{Y}=\operatorname{sqrt}(\mathrm{CD} 4)$

CD4 cell count values were square-root transformed to better approximate a normal distribution [35]. Absolute increase in CD4 count over time on ART was examined using fractional polynomials (FPs), a method which is believed to be more flexible and provides a better fit to the observed data [36]. Because fractional polynomials allow only positive values, time was rescaled to be positive. Eight first-degree and 36 second-degree FP models were used to examine this relationship. Chi square test based on the deviance difference between models was used to select the best-fit curve. Of the eight first-degree models, the model with a power of 0.5 had the smallest deviance and best fit for the data; among the 36 second-degree models, the model with the pair of powers 1,1 (i.e. $y=\beta_{0}+\beta_{1} x+\beta_{2} x(\ln x)$ ) best fits the data. Based on the difference in the deviances of the two models, the second-degree model fits the data significantly better than the first-degree model $\left(\chi^{2}\right.$, $\mathrm{p}<0.0001$ ) so was used in the final modeling.

Univariate analysis was initially performed to examine the associations among each of the nine variables (age, gender, body weight, drug injection use history, HIV clinical stage, TB status, $\mathrm{Hgb}, \mathrm{ALT}$, and $\mathrm{HBsAg} /$ anti-HCV status) and absolute CD4 cell count increase over time on ART. Variables yielding a p-value $<0.2$ were included in a subsequent multivariable analysis [37,38], and entered into the model one at a time starting with the variable having the smallest $\mathrm{p}$-value. The final model included variables with a significance level of 0.05 . All analyses were performed using Stata/SE 13.1 (Stata Corporation, College Station, TX).

\section{Association between HBsAg and Anti-HCV Status and Survival}

Cox regression analysis was used. Person-time at risk was calculated from the date of ART initiation up to either the date of death or date of last visit for those who were LTFU, transferred, or alive. The proportional hazard assumption was tested using Schoenfeld residuals. The design effect due to clustering (clinic) was taken into account in the analysis.

\section{Results}

\section{Descriptive Analysis}

Among the 4,316 patients included in the analysis, the majority were male $(77.8 \%)$; at the time of clinic enrollment, $52.9 \%$ reported that they had previously or were currently using drugs; $68.4 \%$ of had WHO stage III or IV disease; $45.5 \%$ had a CD4 $<50$ cells $/ \mathrm{mm}^{3}$ (measured within 3 months prior ART initiation); $23.5 \%$ had moderate or severe anemia; and $33.6 \%$ had active TB. After imputing for missing $\mathrm{HBsAg}$ and anti-HCV data, $52.4 \%$ tested

HBsAg-negative/anti-HCV-negative, 9.0\%

$\mathrm{HBs}$ Ag-positive/anti-HCV-negative, and $38.6 \%$ anti-HCV -positive (including either HBsAg-positive or HBsAg-negative).

Males were more likely than females to be older $(p<0.0054)$; report injection drug use history $(p<0.0001)$; have higher body weight $(\mathrm{p}<0.0001)$; have abnormal ALT $(p=0.0079)$; have moderate or severe anemia $(p=0.0002)$; have more advanced HIV stage $(p<0.0001)$; and be anti-HCV-positive $(\mathrm{p}<0.0001)$ (Table 1$)$. Males were also more likely to have lower mean CD4 counts measured prior to ART initiation than females $(\mathrm{p}<0.0001)$; overall, the median CD4 count among females (111, IQR=32.5178) was about twice that of males (51.5, IQR=14-134) (Figure 1). 
Table 1. Characteristics of adult HIV patients at clinic enrollment, by gender, HCMC, 2006-2010 ( $\mathrm{n}=4316)$

\begin{tabular}{|c|c|c|c|c|c|}
\hline & \multirow{2}{*}{$\begin{array}{c}\text { Prior to imputation } \\
\text { All } \\
\end{array}$} & \multicolumn{4}{|c|}{ Multiple Imputation } \\
\hline & & All & Men & Women & Wald test \\
\hline \multicolumn{6}{|c|}{ Age (years) } \\
\hline Mean (SD) & $30.0(6.3)$ & $30.0(6.3)$ & $30.1(6.1)$ & $29.9(6.0)$ & \\
\hline Median (Range) & $29(15-75)$ & $29(15-75)$ & $29(16-75)$ & $28(15-60)$ & \\
\hline$<25$ & $616(14.3 \%)$ & $14.3 \%$ & $13.0 \%$ & $18.5 \%$ & \multirow{4}{*}{0.0054} \\
\hline $25-29$ & $1767(40.9 \%)$ & $40.9 \%$ & $41.4 \%$ & $39.5 \%$ & \\
\hline $30-34$ & $1148(26.6 \%)$ & $26.6 \%$ & $27.6 \%$ & $23.2 \%$ & \\
\hline $35+$ & $785(18.2 \%)$ & $18.2 \%$ & $18.0 \%$ & $18.8 \%$ & \\
\hline \multicolumn{6}{|c|}{ Body weight (kg) } \\
\hline$<45$ & $996(23.1 \%)$ & $23.4 \%$ & $16.0 \%$ & $49.2 \%$ & \multirow{5}{*}{$<0.0001$} \\
\hline $45-<50$ & $1180(27.3 \%)$ & $27.6 \%$ & $27.9 \%$ & $27.0 \%$ & \\
\hline $50-<55$ & $1068(24.8 \%)$ & $25.0 \%$ & $27.5 \%$ & $16.0 \%$ & \\
\hline $55+$ & $1024(23.7 \%)$ & $24.0 \%$ & $28.6 \%$ & $7.8 \%$ & \\
\hline Missing & $48(1.1 \%)$ & -- & - & $\begin{array}{c}-- \\
\end{array}$ & \\
\hline \multicolumn{6}{|c|}{ Self-reported history of injection drug use } \\
\hline No & $215(5.0 \%)$ & $14.0 \%$ & $5.9 \%$ & $42.1 \%$ & \multirow{2}{*}{$<0.0001$} \\
\hline Yes & $2282(52.9 \%)$ & $86.0 \%$ & $94.1 \%$ & $57.9 \%$ & \\
\hline Missing & $1819(42.1 \%)$ & -- & - & --- & \\
\hline \multicolumn{6}{|c|}{ Active tuberculosis } \\
\hline No & $2839(65.8 \%)$ & $66.4 \%$ & $62.5 \%$ & $79.8 \%$ & \multirow{2}{*}{$<0.0001$} \\
\hline Yes & $1452(33.6 \%)$ & $33.6 \%$ & $37.5 \%$ & $20.2 \%$ & \\
\hline Missing & $25(0.6 \%)$ & - & - & --- & \\
\hline \multicolumn{6}{|c|}{ WHO HIV clinical stage } \\
\hline $\mathrm{I}-\mathrm{II}$ & $1339(31.0 \%)$ & $31.2 \%$ & $26.7 \%$ & $46.9 \%$ & \multirow{2}{*}{$<0.0001$} \\
\hline III-IV & $2954(68.5 \%)$ & $68.8 \%$ & $73.3 \%$ & $53.1 \%$ & \\
\hline Missing & $23(0.5 \%)$ & -- & - & --- & \\
\hline \multicolumn{6}{|c|}{ Hepatitis } \\
\hline $\begin{array}{c}\text { Anti-HCV-negative and } \\
\text { HBsAg-negative }\end{array}$ & $1377(31.9 \%)$ & $52.4 \%$ & $47.1 \%$ & $71.1 \%$ & \multirow{3}{*}{$<0.0001$} \\
\hline $\begin{array}{l}\text { Anti-HCV-negative and } \\
\text { HBsAg-positive }\end{array}$ & $239(5.5 \%)$ & $9.0 \%$ & $8.6 \%$ & $10.5 \%$ & \\
\hline $\begin{array}{c}\text { Anti-HCV-positive and } \\
\text { (HBsAg-positive or } \\
\text { HBsAg-negative) }\end{array}$ & $1025(23.8 \%)$ & $38.6 \%$ & $44.3 \%$ & $18.4 \%$ & \\
\hline Missing & $1675(38.8 \%)$ & -- & -- & --- & \\
\hline \multicolumn{6}{|c|}{ Pre-ART CD4 (cells $\left./ \mathrm{mm}^{3}\right)$} \\
\hline Median (IQR) & $62(16-150)$ & $62(16-150)$ & $51.5(14-134)$ & $111(32.5-178)$ & \\
\hline$<50$ & $1962(45.5 \%)$ & $45.5 \%$ & $49.3 \%$ & $31.9 \%$ & \multirow{4}{*}{$<0.0001$} \\
\hline $50-<150$ & $1271(29.4 \%)$ & $29.4 \%$ & $28.9 \%$ & $31.3 \%$ & \\
\hline $150-<250$ & $816(18.9 \%)$ & $18.9 \%$ & $15.7 \%$ & $30.1 \%$ & \\
\hline $250+$ & $267(6.2 \%)$ & $6.2 \%$ & $6.1 \%$ & $6.7 \%$ & \\
\hline \multicolumn{6}{|c|}{ ALT* } \\
\hline Normal & $2264(52.5 \%)$ & $52.9 \%$ & $51.6 \%$ & $57.6 \%$ & \multirow{2}{*}{0.0079} \\
\hline Abnormal & $2011(46.6 \%)$ & $47.1 \%$ & $48.4 \%$ & $42.4 \%$ & \\
\hline Missing & $41(0.9 \%)$ & -- & - & --- & \\
\hline \multicolumn{6}{|c|}{ Anemia** } \\
\hline Non or mild anemia & $3141(72.8 \%)$ & $75.6 \%$ & $77.9 \%$ & $67.4 \%$ & \multirow{2}{*}{0.0002} \\
\hline Moderate or severe anemia & $1016(23.5 \%)$ & $24.4 \%$ & $22.1 \%$ & $32.6 \%$ & \\
\hline Missing & $159(3.7 \%)$ & - & -- & --- & \\
\hline
\end{tabular}




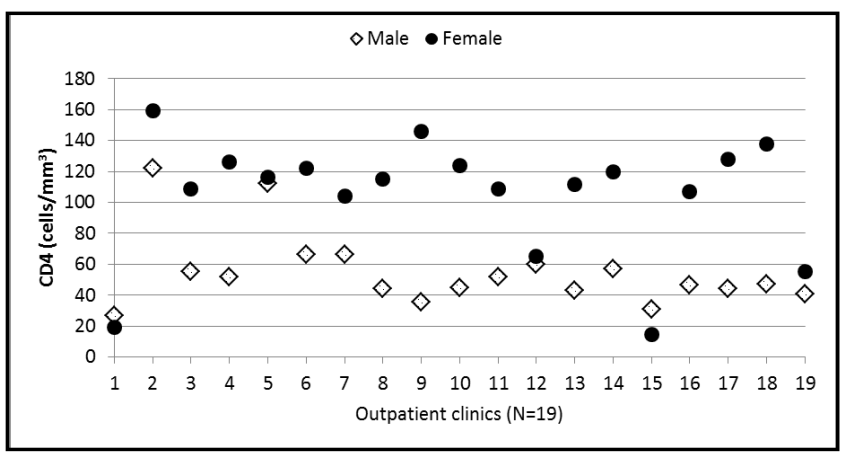

Figure 1. Median baseline CD4 cell count by gender and outpatient clinic

Initial ART regimen was $\mathrm{d} 4 \mathrm{~T}+3 \mathrm{TC}+\mathrm{EFV} / \mathrm{NVP}$ for $92.6 \%$ of patients; $99.5 \%$ used a regimen containing $3 \mathrm{TC}$; only $0.1 \%$ received TDF. Each patient had a CD4 count recorded within 3 months before ART initiation and 1-14 recorded CD4 counts after ART initiation (median 4, IQR = 2-6). Follow-up time on ART varied from 2 months to 3 years (median 1.72 years, $\mathrm{IQR}=0.97-2.44$ ). ART regimens were changed for $29.1 \%$ of individuals during the study period; the majority of the changes were to replace NVP with EFV or d4T with ZDV. Specifically, of those initiating $\mathrm{d} 4 \mathrm{~T} / 3 \mathrm{TC} / \mathrm{NVP}$ who changed to other regimens, $68.6 \%$ changed to $\mathrm{d} 4 \mathrm{~T} / 3 \mathrm{TC} / \mathrm{EFV}$ and $24.3 \%$ to $\mathrm{ZDV} / 3 \mathrm{TC} / \mathrm{NVP}$. At the time of chart abstraction, $87.2 \%$ of individuals remained on ART, 5.7\% were LTFU, $4.3 \%$ had transferred to other clinics, and $2.8 \%$ had died.

\section{Factors Associated with CD4 Response to ART}

Overall, the mixed-effects models of square-root transformed CD4 counts using fractional polynomial approach showed that mean CD4 count at ART initiation was 72 (66-78), and mean CD4 count at 3 years after ART initiation was 364 (343-385). Although mean CD4 cell counts increased over the duration of follow up, the magnitude of $\mathrm{CD} 4$ increase declined over time. In univariate analysis, absolute CD4 gains were significantly smaller initially for males compared with females and for anti-HCV-positive patients compared with HBsAg-negative/anti-HCV-negative and

HBsAg-positive/anti-HCV-negative patients; however, later in follow up, the absolute gains decreased more for females than for males and for HBsAg-negative/anti-HCV-negative and HBsAg-positive/anti-HCV-negative patients than for anti-HCV-positive patients, such that the absolute increase in CD4 count between years 2 and 3 of follow up was significantly greater for males than for females and for anti-HCV-positive patients than for the other 2 hepatitis serology groups.

To determine whether the association between gender and CD4 recovery might be influenced by hepatitis serology, we compared CD4 recovery across categories of combined gender and $\mathrm{HBV}$ or $\mathrm{HCV}$ infection status: $\mathrm{HBsAg}$-negative/anti-HCV-negative males;

HBsAg-positive/anti-HCV-negative males;

anti-HCV-positive males;

HBsAg-negative/anti-HCV-negative females;

HBsAg-positive/anti-HCV-negative females; and anti-HCV-positive females. The mixed-effects models of square-root transformed CD4 counts using fractional polynomial approach showed that CD4 gain over time was significantly different between anti-HCV-positive males and each of the three following groups: $\mathrm{HBs} A g$-negative/anti-HCV-negative females,

HBsAg-positive/anti-HCV-negative females, and HBsAg-negative/anti-HCV-negative males. These associations remained after adjustment for age, HIV clinical stage, TB and anemia status (body weight was no longer statistically significant in the multivariate model). CD4 gain did not differ significantly among the three remaining groups. The estimates were back-transformed to the original scale (CD4 cell counts). Increase in CD4 count by year and hepatitis serology is illustrated in Figure 2 . Overall, CD4 cell count increased over time in all six groups, though the magnitude of the gain decreased over time; the CD4 count gain between years 2 and 3 among anti-HCV-positive males did not decrease as much as it did for other groups. In other words, anti-HCV-positive males had lower gains in CD4 cell count per year soon after ART initiation, but close to the end of their follow-up time the CD4 gains among anti-HCV-positive males were higher than the other three groups. Table 2 presents estimated/modeled mean CD4 cell counts at ART initiation, one year, two years, and three years on ART for the six groups mentioned above. 


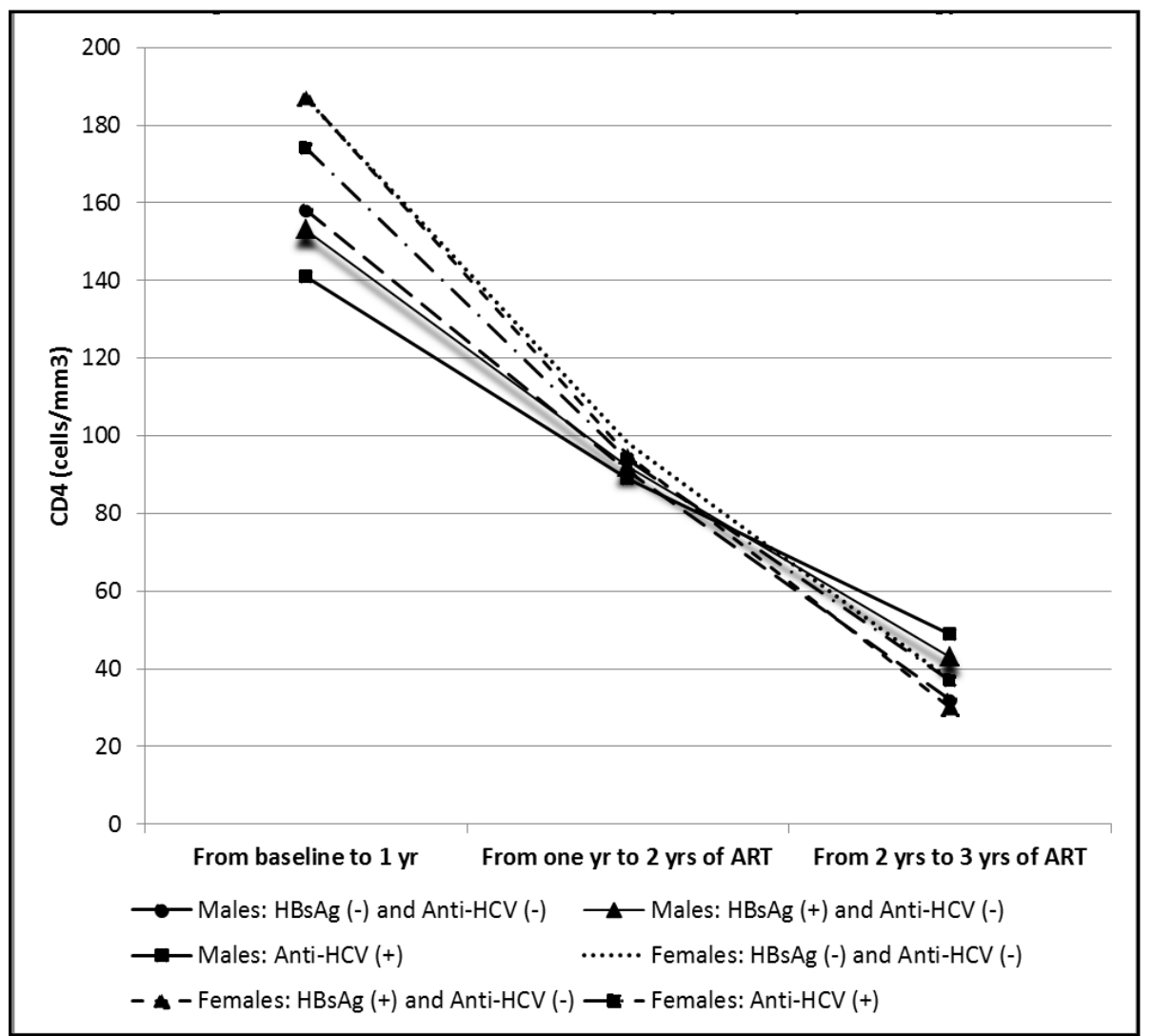

Figure 2. Predicted increase in CD4 count by year and hepatitis serology

Table 2. Modeled* mean CD4 (cells $\left./ \mathrm{mm}^{3}\right)$ and $95 \% \mathrm{CI}$ by gender and $\mathrm{HBV} / \mathrm{HCV}$ markers of infection

\begin{tabular}{|c|c|c|c|c|}
\hline & \multirow{2}{*}{ ART initiation } & \multicolumn{3}{|c|}{ Time after ART initiation } \\
\hline & & 1 year & 2 years & 3 years \\
\hline \multicolumn{5}{|l|}{ Males } \\
\hline Anti-HCV-positive & $\begin{array}{c}77 \\
(68-86)\end{array}$ & $\begin{array}{c}218 \\
(204-232)\end{array}$ & $\begin{array}{c}307 \\
(289-325)\end{array}$ & $\begin{array}{c}356 \\
(327-386)\end{array}$ \\
\hline HBsAg-negative and Anti-HCV-negative & $\begin{array}{c}59 \\
(51-68) \\
\end{array}$ & $\begin{array}{c}217 \\
(203-231) \\
\end{array}$ & $\begin{array}{c}308 \\
(290-326) \\
\end{array}$ & $\begin{array}{c}340 \\
(311-371) \\
\end{array}$ \\
\hline HBsAg-positive and Anti-HCV-negative & $\begin{array}{c}60 \\
(50-71) \\
\end{array}$ & $\begin{array}{c}213 \\
(197-229)\end{array}$ & $\begin{array}{c}305 \\
(283-328) \\
\end{array}$ & $\begin{array}{c}348 \\
(309-391)\end{array}$ \\
\hline \multicolumn{5}{|l|}{ Females } \\
\hline Anti-HCV-positive & $\begin{array}{c}110 \\
(95-127)\end{array}$ & $\begin{array}{c}284 \\
(263-306)\end{array}$ & $\begin{array}{c}378 \\
(351-407)\end{array}$ & $\begin{array}{c}415 \\
(368-465)\end{array}$ \\
\hline HBsAg-negative and Anti-HCV-negative & $\begin{array}{c}103 \\
(92-116) \\
\end{array}$ & $\begin{array}{c}290 \\
(273-309) \\
\end{array}$ & $\begin{array}{c}388 \\
(365-412) \\
\end{array}$ & $\begin{array}{c}425 \\
(389-462) \\
\end{array}$ \\
\hline HBsAg-positive and Anti-HCV-negative & $\begin{array}{c}102 \\
(83-124)\end{array}$ & $\begin{array}{c}289 \\
(264-315)\end{array}$ & $\begin{array}{c}384 \\
(352-416)\end{array}$ & $\begin{array}{c}414 \\
(354-477)\end{array}$ \\
\hline
\end{tabular}

\section{Factors Associated with Survival}

The survival analysis included 4,311 patients, excluding 5 with a missing date of death or last visit.

Overall crude mortality was 15 per 1000 person-years. In univariate analysis, male gender, lower CD4 count, anemia and advanced HIV clinical stage (III/IV) at clinic enrollment were associated with greater risk of mortality over the study period (p-values <0.05); HBsAg and anti-HCV status were not associated with mortality. In multivariable analysis, death rate was lower among females than males $(\mathrm{HR}=0.49,95 \% \mathrm{CI}=0.31-0.78)$ and higher among patients with moderate or severe anemia at OPC registration than among patients with no or mild anemia $(\mathrm{HR}=2.04,95 \% \mathrm{CI}=1.29-3.24)$, after controlling for age and pre-ART CD4 count (Table 3 ). 
Table 3. Factors associated with mortality among adult HIV patients at clinic enrollment, HCMC, 2006-2010 (N=4311)

\begin{tabular}{|c|c|c|c|c|}
\hline \multirow{2}{*}{ Factors } & \multicolumn{2}{|c|}{ Bivariate analysis } & \multicolumn{2}{|c|}{ Multivariable analysis } \\
\hline & $\operatorname{HR}(95 \% \mathrm{CI})$ & $P$-value & $\operatorname{HR}(95 \% \mathrm{CI})$ & $P$-value \\
\hline \multicolumn{5}{|l|}{ Age (years) } \\
\hline$<25$ & 1 & & 1 & \\
\hline $25-29$ & $1.46(0.79-2.71)$ & 0.213 & $1.43(0.78-2.63)$ & 0.234 \\
\hline $30-34$ & $1.57(0.94-2.62)$ & 0.082 & $1.50(0.93-2.44)$ & 0.093 \\
\hline $35+$ & $1.12(0.57-2.21)$ & 0.726 & $1.11(0.56-2.19)$ & 0.755 \\
\hline \multicolumn{5}{|l|}{ Gender } \\
\hline Male & 1 & & 1 & \\
\hline Female & $0.49(0.33-0.72)$ & 0.001 & $0.51(0.34-0.75)$ & 0.002 \\
\hline \multicolumn{5}{|l|}{ Body weight (kg) } \\
\hline$<45$ & $1.49(0.86-2.58)$ & 0.139 & & \\
\hline $45-<50$ & $1.06(0.48-2.34)$ & 0.883 & & \\
\hline $50-<55$ & $0.98(0.51-1.88)$ & 0.936 & & \\
\hline $55+$ & 1 & & & \\
\hline \multicolumn{5}{|l|}{ Self-reported injection drug use } \\
\hline No & 1 & & & \\
\hline Yes & $1.20(0.63-2.29)$ & 0.556 & & \\
\hline \multicolumn{5}{|l|}{ Active tuberculosis } \\
\hline No & 1 & & & \\
\hline Yes & $1.26(0.94-1.70)$ & 0.118 & & \\
\hline \multicolumn{5}{|l|}{ WHO HIV clinical stage } \\
\hline I-II & 1 & & & \\
\hline III-IV & $1.77(1.06-2.95)$ & 0.032 & & \\
\hline \multicolumn{5}{|l|}{ Hepatitis } \\
\hline HBsAg-negative and anti-HCV-negative & 1 & & & \\
\hline HBsAg-positive and anti-HCV- negative & $1.07(0.54-2.11)$ & 0.829 & & \\
\hline $\begin{array}{l}\text { Anti-HCV-positive and HBsAg-positive or } \\
\text { HBsAg-negative }\end{array}$ & $1.08(0.56-2.06)$ & 0.813 & & \\
\hline \multicolumn{5}{|l|}{ CD4 $\left(\right.$ cells $\left./ \mathrm{mm}^{3}\right)$} \\
\hline$<50$ & 1 & & 1 & \\
\hline $50-<150$ & $0.50(0.27-0.92)$ & 0.028 & $0.62(0.33-1.18)$ & 0.136 \\
\hline $150-<250$ & $0.14(0.02-1.01)$ & 0.051 & $0.18(0.02-1.27)$ & 0.081 \\
\hline $250+$ & $0.63(0.31-1.28)$ & 0.187 & $0.80(0.40-1.58)$ & 0.498 \\
\hline \multicolumn{5}{|l|}{ ALT* } \\
\hline Normal & 1 & & & \\
\hline Abnormal & $1.30(0.94-1.81)$ & 0.090 & & \\
\hline \multicolumn{5}{|l|}{ Anemia** } \\
\hline Non or mild anemia & 1 & & 1 & \\
\hline Moderate or severe anemia & $2.13(1.32-3.44)$ & 0.004 & $2.04(1.29-3.24)$ & 0.005 \\
\hline
\end{tabular}

\section{Discussion}

This study examined the association between HBV and $\mathrm{HCV}$ co-infection markers and outcomes of HIV-suppressive ART (i.e. absolute CD4 cell count increase, and death) before first line
$\mathrm{TDF}+3 \mathrm{TC} / \mathrm{FTC}+\mathrm{EFV} / \mathrm{NVP}$ implementation in HCMC. Compared to patients without evidence of $\mathrm{HBV}$ or $\mathrm{HCV}$ infection, anti-HCV-positive patients initiated ART at higher CD4 counts but had significantly lower CD4 gain soon after ART initiation, but close to the end of their follow-up time the $\mathrm{CD} 4$ gain among anti-HCV-positive 
males was higher. Specifically, compared to anti-HCV-negative females (regardless of HBsAg status), and HBsAg-negative/anti-HCV-negative males, anti-HCV-positive males had the lowest CD4 gain in the first two years of ART, but the CD4 gain between two and three years of ART was higher than the other three groups: HBsAg-negative/anti-HCV-negative females,

$\mathrm{HBs} A$ g-positive/anti-HCV-negative females, and HBsAg-negative/anti-HCV-negative males. There was no significant difference in CD4 recovery among other serological groups. Neither current HBV infection nor the presence of anti-HCV was statistically associated with death among the HIV outpatients who initiated ART during 2006-2010.

The finding of lower CD4 recovery after ART initiation among anti-HCV-positive patients is consistent with the recent meta-analysis by Miller et al., reporting a statistically significantly smaller rise in $\mathrm{CD} 4$ during ART among HIV-HCV co-infected patients (defined by anti-HCV or HCV RNA) than among those without HCV co-infection [13]. Our findings show that anti-HCV-positive males had smaller CD4 gains in the first two years of ART, but greater CD4 gains between two and three years of ART than in HBsAg-negative/anti-HCV-negative females,

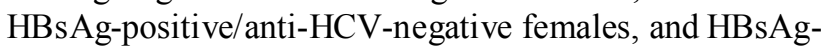
negative/anti-HCV-negative males. Because most patients were followed up between 12 and 24 months in the studies included in the meta-analysis by Miller et al., the long-term impact was unknown. It is possible that anti-HCV-positive individuals who could be on ART for a long time, e.g. three years, did not have current hepatitis $\mathrm{C}$. It is estimated about $15-45 \%$ of people infected with HCV clear the infection are still positive for anti-HCV antibodies [39]. Unfortunately, we were not able to distinguish between current $\mathrm{HCV}$ infection and previous exposure to $\mathrm{HCV}$ in this study using anti-HCV-positive marker, some anti-HCV-positive individuals may have cleared their $\mathrm{HCV}$ infection leading to underestimation of the negative impact of $\mathrm{HCV}$ infection on CD4 recovery.

In the study by Griensven et al. [10], they found that CD4 cell count increase was statistically significant lesser among HIV patients with HBV-positive than those with HBV-negative over a median follow-up time of 4.3 years $(\mathrm{IQR}=2.1-4.7)$. However, the difference was not statistically significant between those with HCV-positive and those with HCV-negative in the same study [10]. In our study, CD4 recovery on ART was not statistically significantly different among other serological groups; reduced sample sizes of the strata could account for the lack of statistical significance across the multiple classifications. Even if the differences were statistically significant, they were small and may not be clinically important.

Higher pre-ART CD4 levels among females and higher CD4 recovery among females compared to males has been reported elsewhere, thought to be partially due to later male access to HIV services and poorer male ART adherence [40-43]. To the best of our knowledge, however, the potential joint effect of male gender and anti-HCV-positive status has not been previously reported.

To reduce bias, the current analysis specifically adjusted for gender differences in baseline CD4 levels but did not adjust for other gender-related behaviors such as cigarette smoking and alcohol consumption which are more prevalent among HIV-infected males than HIV-infected females $[40,41]$, and found to be associated with poorer ART adherence $[42,43]$. However, we cannot explain why anti-HCV-positive males and females had higher baseline CD4 levels than the other serogroups.

The lack of statistically significant associations between HBsAg-positive and anti-HCV-positive serostatus and mortality among HIV infected adults on ART during the 2006-2010 study period (median time on ART of 1.72 years) contrasts with a retrospective study of Cambodia HIV+ infected patients receiving 3TC-based ART during 2003-2012 [10]. That study showed no statistically significant association between $\mathrm{HBV}$ or $\mathrm{HCV}$ and mortality among HIV-infected patients within the first year of ART; however, HIV/HBV or HIV/HCV co-infected patients were two to three times more likely to die after the first year of ART compared to HIV+ patients without evidence of $\mathrm{HBV}$ or $\mathrm{HCV}$ over the median follow-up time of 4.3 years (IQR=2.1-4.7) [10]. Our shorter follow-up time (median 1.72 years, IQR=0.97-2.44) might partially explain the contrast. Notably, although over $99.0 \%$ of the individuals in this analysis received 3TC-containing ART, the follow-up of 1.72 years was possibly too short to see the emergence of $\mathrm{HBV}$ resistance to $3 \mathrm{TC}$ and waning $3 \mathrm{TC}$ suppression of HBV; the previous research showed it may take a longer time to develop 3TC resistance (median 40 months) [44]. Similarly, although HCV infection was not being treated, the study period may have been too short to observe the effects of HCV co-infection on HIV outcomes in a younger patient population - approximately $63 \%$ of our study population was 30 years of age or younger vs only $31 \%$ in that study. Several U.S. studies among HIV-infected individuals showed no impact of HBV and $\mathrm{HCV}$ coinfections on development of AIDS, deaths, immunologic response, or viral load $[45,46]$; differences in ART regimens, ART access and options for $\mathrm{HCV}$ treatment might mitigate coinfection impact in those settings. In our study, co-infection with HBV (HBsAg-positive) and/or exposure to $\mathrm{HCV}$ (anti-HCV-positive) did not seem to have a substantial effect on mortality. Also, a hazard ratio of 1.07 to 1.08 (table 3) did not seem to be clinically significant. Our findings might reflect the real status among HIV infected adults on ART during the 2006-2010 study period as AIDS-related death still remained the leading cause of death among HIV infected patients. A review of $5612 \mathrm{HIV}$ infected patients on ART over a period of 71 months in 
India reported that the majority of deaths $(67 \%)$ were due to AIDS-related causes [17].

The current study has several strengths. It included a large number of HIV outpatients drawn from community-based clinics in the largest city in Vietnam; HCMC accounts for over one-quarter $(28 \%)$ of all Vietnam ART patients. CD4 cell counts were collected at multiple follow-up visits in outpatient programmatic settings. However, several limitations exist. Median follow-up time from ART initiation in this study was nearly two years; the timing of ART initiation and duration of treatment within the study period varied so might not provide an adequate clinical window for observing the effects of $\mathrm{HBV} / \mathrm{HCV}$ co-infection on clinical or immunological outcomes of ART patients. In addition, as screening for hepatitis B and $\mathrm{C}$ virus among HIV-infected patients was not required during 2006-2010, and depended on the availability of project based funding, many patients did not have hepatitis serology. Missing HBsAg and anti-HCV data might not be random, but any bias related to missing $\mathrm{HBsAg}$ and anti-HCV data may be minimal or non-existent since baseline differences in age, gender, HIV clinical stage, and CD4 were not significant between patients with recorded HBsAg and/or anti-HCV results and those without. About two-thirds $(61.5 \%)$ of the total existing records were included in the analysis, and the prevalence of anti-HCV-positive was not significantly different (39\% vs. $42 \%$ ) between patients included and excluded; however, mortality rate was much higher among excluded than included patients $(17 \%$ vs. $3 \%)$ which suggests that selection bias may exist. Specifically, the study missed individuals who did not have a follow-up CD4 because they might not survive through the follow-up time point, among other reasons. This was evidenced by the fact that majority of deaths among the excluded group (86.8\%) were among those who did not have a follow-up CD4. Therefore, our findings can only be applied to those who had a valid pre-ART CD4 count within three months prior to ART initiation and at least one follow-up CD4 count measured two months or more after the start of ART in order to assess outcomes of ART.

\section{Conclusions}

Over $50 \%$ of patients enrolling in community based clinics in HCMC from 2006-2010 were coinfected with $\mathrm{HBV}$ and/or had evidence of past or current $\mathrm{HCV}$ infection defined by positive anti-HCV serology. HCV exposure and male gender negatively impacted CD4 gain soon after ART initiation but, in the long term, CD4 gain was greatest among males with prior $\mathrm{HCV}$ exposure; this unexpected finding might have resulted from bias potentially introduced by a healthy population selection effect. Although statistically significant, the differences were small and may not be clinically important.
Co-infection with HBV (HBsAg-positive) and/or exposure to $\mathrm{HCV}$ (anti-HCV-positive) does not seem to have substantial effects on outcomes of patients who were on non-TDF-containing ART during a median follow-up of 1.72 years (e.g. CD4 count recovery and mortality). It may take a longer time for assessing effects of co-infection with HBV and/or HCV on ART outcomes, and such assessments should focus on those with positive $\mathrm{HCV}$ RNA, instead of positive anti-HCV.

\section{Acknowledgements}

The authors would like to thank the data collection and entry team from the HCMC PAC and the staff from the HCMC HIV clinics where data was collected. We also thank the technical advice of Dr. Sheryl Lyss.

\section{REFERENCES}

[1] WHO. Hepatitis B n.d. http://www.wpro.who.int/vietnam/topics/hepatitis/factsheet /en/ (accessed October 27, 2017).

[2] Do SH, Yamada H, Fujimoto M, Ohisa M, Matsuo J, Akita T, et al. High prevalences of hepatitis $\mathrm{B}$ and $\mathrm{C}$ virus infections among adults living in Binh Thuan province, Vietnam. Hepatol Res 2015; 45: 259-68.

[3] Dunford L, Carr MJ, Dean J, Nguyen LT, Ta Thi TH, Nguyen BT, et al. A multicentre molecular analysis of hepatitis B and blood-borne virus coinfections in Viet Nam. PLoS One 2012; 7.

[4] Kallman JB, Tran S, Arsalla A, Haddad D, Stepanova M, Fang Y, et al. Vietnamese community screening for hepatitis $B$ virus and hepatitis C virus. J Viral Hepat 2011; 18: 70-6.

[5] Sereno L, Mesquita F, Kato M, Jacka D, Nguyen TT Van, Nguyen TN. Epidemiology, responses, and way forward: the silent epidemic of viral hepatitis and HIV coinfection in Vietnam. J Int Assoc Physicians AIDS Care (Chic) 2012; 11: 311-20.

[6] Nguyen VTT, McLaws M-L, Dore GJ. Prevalence and risk factors for hepatitis $\mathrm{C}$ infection in rural north Vietnam. Hepatol Int 2007; 1: 387-93.

[7] Nadol P, O'Connor S, Duong H, Le LVN, Thang PH, Tram $\mathrm{TH}$, et al. Findings from Integrated Behavioral and Biologic Survey among males who inject drugs (MWID)-Vietnam, 2009-2010: Evidence of the need for an integrated response to $\mathrm{HIV}$, hepatitis B virus, and hepatitis $\mathrm{C}$ virus. PLoS One $2015 ; 10$.

[8] Quan VM, Go VF, Nam L Van, Bergenstrom A, Thuoc NP, Zenilman J, et al. Risks for HIV, HBV, and HCV infections among male injection drug users in northern Vietnam: A case-control study. AIDS Care 2009; 21: 7-16.

[9] Thio, Chloe L. Smeaton L, Saulynas M, Hwang H, Saravanan S, Saravan S et al. Characterization of HIV-HBV coinfection in a multinational HIV-infected cohort. AIDS 
2013; $27:$ 191-201.

[10] Van Griensven J, Phirum L, Choun K, Thai S, De Weggheleire A, Lynen L. Hepatitis B and C co-infection among HIV-infected adults while on antiretroviral treatment: Long-term survival, CD4 cell count recovery and antiretroviral toxicity in Cambodia. PLoS One 2014;9.

[11] Thio CL, Seaberg EC, Skolasky R, Phair J, Visscher B, Muñoz A, et al. HIV-1, hepatitis B virus, and risk of liver-related mortality in the Multicenter Cohort Study (MACS). Lancet 2002; 360: 1921-6.

[12] Chun HM, Roediger MP, Hullsiek KH, Thio CL, Agan BK, Bradley WP, et al. Hepatitis B virus coinfection negatively impacts HIV outcomes in HIV seroconverters. J Infect Dis 2012; 205: 185-93.

[13] Miller MF, Haley C, Koziel MJ, Rowley CF. Impact of hepatitis $\mathrm{C}$ virus on immune restoration in HIV-infected patients who start highly active antiretroviral therapy: a meta-analysis. Clin Infect Dis 2005; 41: 713-20.

[14] Benhamou Y, Bochet M, Thibault V, Di Martino V, Caumes $\mathrm{E}$, Bricaire F, et al. Long-term incidence of hepatitis B virus resistance to lamivudine in human immunodeficiency virus-infected patients. Hepatology 1999; 30:1302-6.

[15] Avihingsanon A, Lewin SR, Kerr S, Chang JJ, Piyawat K, Napissanant N, et al. Efficacy of tenofovir disoproxil fumarate/emtricitabine compared with emtricitabine alone in antiretroviral-naive HIV-HBV coinfection in Thailand. Antivir Ther 2010; 15: 917-22.

[16] Price H, Dunn D, Pillay D, Bani-Sadr F, de Vries-Sluijs T, Jain MK, et al. Suppression of HBV by Tenofovir in HBV/HIV Coinfected Patients: A Systematic Review and Meta-Analysis. PLoS One 2013; 8.

[17] Bhattacharya D, Thio CL. Review of hepatitis B therapeutics. Clin Infect Dis 2010; 51: 1201-8.

[18] de Vries-Sluijs TE, Reijnders JG, Hansen BE, Zaaijer HL, Prins JM, Pas SD, et al. Long-term therapy with tenofovir is effective for patients co-infected with human immunodeficiency virus and hepatitis $\mathrm{B}$ virus. Gastroenterology 2010; 139: 1934-41.

[19] Martín-Carbonero L, Teixeira T, Poveda E, Plaza Z, Vispo E, González-Lahoz J, et al. Clinical and virological outcomes in HIV-infected patients with chronic hepatitis $B$ on long-term nucleos(t)ide analogues. AIDS 2011; 25: 73-9.

[20] Zoutendijk R, Zaaijer HL, De Vries-Sluijs TEMS, Reijnders JGP, Mulder JW, Kroon FP, et al. Hepatitis B surface antigen declines and clearance during long-term tenofovir therapy in patients coinfected with HBV and HIV. J Infect Dis 2012; 206: 974-80.

[21] Stewart B, Jobarteh ML, Sarge-Njie R, Alabi A, de Silva T, Peterson $\mathrm{K}$, et al. Emergence of $\mathrm{HBV}$ resistance to lamivudine (3TC) in HIV/HBV co-infected patients in The Gambia, West Africa. BMC Res Notes 2011; 4: 561.

[22] Khamduang W, Gaudy-Graffin C, Ngo-Giang-Huong N, Jourdain G, Moreau A, Luekamlung N, et al. Long-term hepatitis B virus (HBV) response to Lamivudine-containing highly active antiretroviral therapy in HIV-HBV co-infected patients in Thailand. PLoS One 2012; 7.

[23] Squibb B-M. Prescribing Information Stavudine.
Interactions 1998; 50: 1-25.

[24] Thio CL, Locarnini S. Treatment of HIV/HBV coinfection: Clinical and virologic issues. AIDS Rev 2007; 9: 40-53.

[25] Hsieh TH, Tseng TC, Liu CJ, Lai MY, Chen PJ, Hsieh HL, et al. Hepatitis B virus genotype B has an earlier emergence of lamivudine resistance than genotype C. Antivir Ther 2009; $14: 1157-63$

[26] Shiffman ML. Hepatitis C virus therapy in the direct acting antiviral era. Curr Opin Gastroenterol 2014;30:217-22.

[27] MOH. Guidelines for HIV/AIDS diagnosis, treatment, and care 2011

[28] Hann HW, Wan S, Myers RE, Hann RS, Xing J, Chen B, et al. Comprehensive Analysis of Common Serum Liver Enzymes as Prospective Predictors of Hepatocellular Carcinoma in HBV Patients. PLoS One 2012; 7.

[29] Who, Chan M. Haemoglobin concentrations for the diagnosis of anaemia and assessment of severity. Geneva, Switz World Heal Organ 2011:1-6.

[30] $\mathrm{MOH}$. Guidelines for HIV/AIDS diagnosis, treatment, and care. 2005

[31] WHO. Guidelines for HIV/AIDS diagnosis, treatment, and care. 2009.

[32] MOH. Circular No. 32/2013/TT-BYT. 2013.

[33] StataCorp. Stata multiple imputation reference manual. 2013.

[34] Harvey Goldstein. 3-level Models and more Complex Hierarchical Structures. Multilevel Stat. Model. 4th Edition, 2010 .

[35] Nash D, Katyal M, Brinkhof MWG, Keiser O, May M, Hughes R, et al. Long-term immunologic response to antiretroviral therapy in low-income countries: a collaborative analysis of prospective studies. AIDS 2008; 22: 2291-302.

[36] Royston P, Sauerbrei W. Multivariable Model-Building: A Pragmatic Approach to Regression Analysis based on Fractional Polynomials for Modelling Continuous Variables. 2008.

[37] Mclean RC, Nazarian SM, Gluckman TJ, Schulman SP, Thiemann DR, Shapiro EP, et al. Relative importance of patient, procedural and anatomic risk factors for early vein graft thrombosis after coronary artery bypass graft surgery. J Cardiovasc Surg (Torino) 2011; 52: 877-85

[38] Ansari-Moghaddam A, Ostovaneh MR, Sharifi Mood B, Sanei-Moghaddam E, Modabbernia A, Poustchi H. Seroprevalence of Hepatitis B Surface Antigen and Anti Hepatitis C Antibody in Zahedan City, Iran: A Population-Based Study. Hepat Mon 2012; 12.

[39] WHO. Hepatitis C 2015 n.d. http://www.who.int/mediacentre/factsheets/fs164/en/ (accessed May 1, 2015).

[40] Le TKT, Dang HH, Nguyen DV, Tien PH, M.A Plant. Alcohol Use, Risk Taking, Leisure Activities and Health Care Use Among Young People in Northern Vietnam. Cent Asian J Glob Heal 2013; 2: 1-6. 
[41] Nguyen NPT, Tran BX, Hwang LY, Markham CM, Swartz MD, Phan HTT, et al. Prevalence of cigarette smoking and associated factors in a large sample of HIV-positive patients receiving antiretroviral therapy in Vietnam. PLoS One 2015; 10.

[42] Do HM, Dunne MP, Kato M, Pham C V, Nguyen K V. Factors associated with suboptimal adherence to antiretroviral therapy in Viet Nam: a cross-sectional study using audio computer-assisted self-interview (ACASI). BMC Infect Dis 2013; 13: 154.

[43] Nguyen NTP, Tran BX, Hwang LY, Markham CM, Swartz $\mathrm{MD}$, Vidrine JI, et al. Effects of cigarette smoking and nicotine dependence on adherence to antiretroviral therapy among HIV-positive patients in Vietnam. AIDS Care 2016; 28: 359-64.

[44] Ramos B, Núñez M, Martín-Carbonero L, Sheldon J, Rios P, Labarga $\mathrm{P}$, et al. Hepatitis B virus genotypes and lamivudine resistance mutations in HIV/hepatitis B virus-coinfected patients. J Acquir Immune Defic Syndr 2007; 44: 557-61.

[45] Sulkowski MS, Moore RD, Chaisson RE, Thomas DL. Hepatitis C and Progression of HIV Disease. Jama 2002; 288: 199-206.

[46] Sullivan PS, Hanson DL, Teshale EH, Wotring LL, Brooks JT. Effect of hepatitis C infection on progression of HIV disease and early response to initial antiretroviral therapy. Aids 2006; 20: 1171-9. 